UDC: (811.111'276.6:37):61 https://doi.org/10.22190/JTESAP2002061K

\title{
PRAGMATIC ASPECTS OF ACADEMIC WRITING IN HEALTH CARE
}

\author{
Leontina Kerničan $^{1}$, Nadežda Stojković ${ }^{2}$ \\ ${ }^{1}$ Faculty of Pharmacy, University of Belgrade, Serbia \\ E-mail: leontina@pharmacy.bg.ac.rs \\ ${ }^{2}$ Faculty of Electronic Engineering, University of Niš, Serbia \\ E-mail: nadezda.stojkovic@elfak.ni.ac.rs
}

\begin{abstract}
A clear delineation is obvious to understand specific aspects regarding the use of academic writing in health care. Thus, more pragmatic and less general aspects of academic writing for medical purposes will be taken into account. Due to solid experience in students' education of LSP at medical faculties, we are delighted to share our academic experience primarily with students as well as with our colleagues. The paper will be focused on emphasizing the critical points of structuring medical texts. Namely, it will present the path of text structuring to help readers understand the specific aspects of high relevance for medical authors. Also, it will draw attention to the role of health care practitioners as well as how they should evaluate this aspect in their professional communication. Furthermore, we would like to pay attention to approaching fundamental problems in academic writing in health care.
\end{abstract}

Key words: academic writing,health care, pragmatic approach

\section{INTRODUCTION}

The paper is aimed to give an insight into several issues. In the first part, we would like to point out the differences between general and technical language as well as to define the characteristics of formal and informal communication. This brief reference is important to review the basic facts on using a formal style in academic writing to write correctly and appropriately. In the second, that is the core part, we shall be focused on the pragmatic aspects of academic writing, i.e. how to structure a text to help readers understand the specific aspects of high relevance for medical authors and to draw attention to the role of health care practitioners.

Academic writing refers to a style of expression that researchers use to define the research results of any type in their specific areas of expertise. In writing an academic paper, both in pharmacy and other medical areas, we use many written forms, such as scientific papers, scientific articles, data presentations, case studies, abstracts, summaries, etc. They are formulated differently due to their specific purposes, but they include the same logical and structural components. All these various types of written forms must entail a brief introduction, methods used to obtain results, discussion on the case or study results and a logical conclusion. This approach will indispensably lead to a new concept of communication in a more structured formal style that will include a clear focus on the research problem in

Submitted February $28^{\text {th }}, 2020$, accepted for publication March $14^{\text {th }}, 2020$ 
question, i.e. the use of more precise words and phrases focused on the matter of research and technical vocabulary. In academic writing, the use of technical vocabulary is also of substantial importance. General language is defined as a language with thematic variety, and multipurpose usage focused on developing general competences of oral and written communication, while technical language or the language for specific purposes (LSP) is aimed at developing the specific competences of oral and written communication in a professional context. The characteristics of technical language are important both for students and graduate health care practitioners, as the common practice of the English language use for students and health care professionals includes mostly general language used in informal style.

Regarding the characteristics of informal and formal styles in written communication, informal style is certainly more common in casual communication as it includes less rigid style directly addressing those whom we know very well or who are our peers. Due to this fact, it certainly implies less formal sentence constructions, no introductive phrases and less emphasis on grammar, spelling and punctuation.

Formal written communication entails more rigidly structured sentences, more formal tone and more standard language, i.e. more emphasis on grammar and spelling as well as an appropriate style that implies addressing people whom we do not know very well and who are not our peers. The point of formal communication, especially in a written form is not exclusively to send information but to apply the appropriate style of addressing to fulfil the objectives of communication. Formal professional academic communication is more specific compared to the characteristics mentioned above because it additionally includes technical language. Furthermore, scholarly communication in the professional use of health care practitioners is quite specific because it has an interdisciplinary deep pragmatic context that will be discussed concerning technical terms use.

Academic writing for both general and professional purposes includes five steps: prewriting, writing, rewriting, finalising and proofreading. Prewriting is focused on making a writing concept by logical organisation of basic ideas that will follow research aims. It comprises two steps: 1 . defining a topic, i.e. knowing very well the specifics and aims of the topic 2 . specifying the basic ideas that will be developed in the paper. In writing, we have to write freely about main ideas taking into account our professional experience and scientific relevance. This process often includes many grammar and spelling mistakes of non-native speakers. Rewriting is focused on reading and correction of grammar, orthographic and spelling mistakes. In the final step, a text will be checked for its readability. This final part of writing will include a text overview from a pragmatic point of view. This means to refer back to the specifics. Furthermore, this will also include a profound writer's capacity to convey the essential information given previously as well as to be focused on the crucial aspects of the matter in view.

As mentioned in Faber P. at all (2012: 177) "pragmatics deals with meaning arising from language in context, in other words, the meaning intended by the speaker or text sender and understood by the listener or text receiver... As such, pragmatics focuses on the effect of context on communicative behavior as well as on how inferences are made by the receiver in order to arrive at the final interpretation of an utterance." Thus in writing academic medical texts, health care practitioners are recommended to take into account this approach.

When considering the technical criteria of pragmatic review, the use of connecting phrases to improve text readability is of vital importance. Furthermore, the most appropriate polite introductive or argumentative connecting phrases will help readers to understand and 
reconsider facts, results and conclusions, and to identify objectives in the light of their pragmatic context. Finally, a proofreader may check appropriateness from the technical point of view, but before we leave a text to a proofreader, all aspects mentioned above, especially technical and pragmatic elements must be perfectly agreed upon. Proofreading means to intervene in a paper with minimal corrections.

\section{METHODS AND AIMS}

The theoretical background of academic writing for medical purposes will be considered through a practical demonstration of gradual writing process designed to develop writing abilities of health care practitioners bearing in mind their pragmatic overview.

As there are specific aspects of writing academically in pharmacy besides general ones, they will be analysed based on a characteristic excerpt taken from a scientific paper on patients' rights. The text that will be further reviewed was presented by a lecturer in the second step of writing. The lecturer's purpose was to give an outline of the most specific mistakes noticed in practical exercising with pharmacy students. The omissions range from general spelling and grammar mistakes to the incorrect use of terminology and academic style.

Before starting the review, the lecturer presented the specifics of the topic and gave appropriate instructions regarding the step of text review. The students were invited to review the text in order to analyse further their inserts and changes. In each step, the most important remarks were made afterwards in the corrections in the text. Also, a few suggestions of the lecturer were presented before students' review that should be taken into account in the course of review.

\section{RESULtS}

In the first step of prewriting, the lecturer gave the title of the topic, its specifics and the text. The students were asked to check the text for grammar and spelling mistakes. The errors that were intentionally made in the text were the most common in academic writing of non-native speakers.

I The given pattern with the title and specifics:

Goverments involved in the organization of health care service and new systems created laws. They have clearly defined roles for all health team members took care on receiving an adequate therapy for a patient. The patients Bill of Rights require that patients have be treated with respect. Some violations against patient rights are asault, negligence, invasion of privacy, abuse of verble communication. Asault are verble or physical treat that cause harm, injury or fear. Failure to give proper care to patients is called negligense. Discussing informations about patients without their consent is unlawfully. Failure to obey these areas makes you non-liable or legally irresponsible.

The title: Patients' Rights in Health Care

The specifics and aims: prevention, liability, patients' rights, violation, health care, health care law. 
II The student's results after their first review in writing:

Goverments involved in the organization of health care service and new systems created laws. They have clearly defined roles for all health team members who take care on receiving an adequate therapy for a patient. The patients Bill of Rights / Patients bill of rights require that patients have to be treated with respect. Some violations against patient rights are asault, negligence, invasion of privacy, abuse of verbal communication. Assault is verbal or physical treat that cause harm, injury or fear. Failure to give proper care to patients is called negligence. Discussing informations about patients without their consent is unlawful. Failure to obey these areas makes you non-liable or legally irresponsible.

The grammar and spelling mistakes that they did not catch in the pattern were as follows (will be reconsidered in the discussion):

III The student's results after their rewriting and teachers' instructions (changes were marked):

- The goverments involved in the organization of health care service and new systems created laws. They have clearly defined roles for all health team members who take care on receiving an adequate therapy for a patient. The Patients' Bill of Rights requires that patients have to be treated with respect. Some violations against patients' rights are assault, negligence, invasion of privacy, abuse of verble communication. Assault is verbal or physical treat that cause harm, injury or fear. Failure to give proper care to patients is called neglegence. Discussing information about patients without their consent is unlawful. Failure to obey these areas makes you non-liable or legally irresponsible.

IV The student's sample before finalysing (designed to be proceeded in two steps):

- The goverments involved in the organization of health care service and new systems created laws. They have clearly defined roles for all health team members who take careon receiving an adequate therapy for a patient. The Patients' Bill of Rights requires that patients have to be treated with respect. Some violations against patients' rights are assault, negligence, invasion of privacy, abuse of verbal communication. Assault is a verbal or physical treat that cause injury or fear. Failure to giveproper care to patients is called negligence. Discussing information about patients without their consent is unlawful. Failure to obey these areas makes you non-liable or legally irresponsible.

Before proceeding to finalise, students wereaddressed a few underlined remarks that should be reconsidered in order to meet the specifics of the topic. Namely, they had to avoid using relative pronouns in order to summarize the text. They were advised to make these changes to improve text readability, i.e. to work more on the technical functionality of thetext. The underlined phrases were the focus of students' review:

The students' sample after the first step of finalising:

- The goverments involved in the organization of health care service and new systems created laws. They have clearly defined roles for all health team members taking careon receiving an adequate therapy for a patient. The Patients' Bill of Rights requires that patients must be treated with respect and dignity. Some violations against patients' rights are assault, negligence, invasion of privacy and verbal communication abuse. Assault is a verbal or physical treat causingan injury or fear. Failure of givingproper care to patients is called negligence. Discussing information about patients without their consent is unlawful. Failure to obey these laws makes one non-liable and legally irresponsible.

In the second step of finalising, the lecturer invited the students to use appropriate linking phrases in order to work on pragmatic aspects of the topic. They were also allowed 
to make necessary changes in words or phrases to meet the specifics. The final purpose of this step was to reshape the idea of health care law in an argumentative text. They were challenged to point out the most important pragmatic aspects of the topic.

The students' sample after the second step of finalising (without lecturers' comments or suggestions):

- The goverments involved in the organization of health care service and new systems created laws having clearly defined roles for all health team members taking care on receiving an adequate therapy for a patient. The Patients' Bill of Rights requires that patients must be treated with respect and dignity. Some violations against patients' rights are assault, negligence, invasion of privacy and verbal communication abuse. Assault is in fact a verbal or physical treat causingan injury or fear. Failure of giving proper care to patients is called negligence. Also, discussing information about patients without their consent is unlawful. Accordingly / Therefore / Thus, failure to obey these laws makes one non-liable and legally irresponsible.

As the final version did not attain the objectives of the pragmatic view discussed in the introductive part, the lecturer re-evaluated the specifics and gave the last version. He drew students' attention to the following key aspects of health care (underlined below): Patients' Rights in Health Care

The specifics and aims: prevention, liability, patients' rights, violation, health care, health care law.

Health care is one of the fundamental aspects in respecting human rights. In protecting patients' rights, as the most sensible aspect of human rights, many instruments of law took part.

Goverments involved in the organization of health care service / managing health legislation and new systems created laws having / with clearly defined roles for all health team members taking care on receiving an adequate therapy. The Patients' Bill of Rights, as one of the crucial documents in view of patients' care, requires that patients must be treated with dignity. Accordingly, some violations against patients' rights shall be considered in view of four criteria: assault, negligence, invasion of privacy and verbal communication abuse. Assault is a verbal or physical treat causing an injury or fear. Failure of giving proper care to patients is called negligence. Discussing information about patients without their consent, i.e. invasion of privacy or verbal communication abuse is unlawful.

Consequently, failing to obey these criteria will certainly make one non-liable and legally irresponsible, due to one's legal irresponsibility will certainly further break / violate the fundamental human rights of protecting people in need of health care at its different levels.

\section{DISCUSSION}

We compared the results of students' reviews, including partial corrections to the suggested versions including the entirely corrected text. As the prewriting concept was given in advance, the analysis will elucidate the facts from the second phase.

The results of the second phase of writing show that students did not correct all the mistakes from the pattern. The use of only small letters in writing a phrase denoting the law in pharmaceutical legislation shows that no one realised the figurative sense of this 
noun phrase, possibly because they did not perceive it as a specific technical term. In the other review they gave, they perhaps used a capital letter only at the beginning of the phrase by the analogy with Serbian orthographic rules, although they probably did not understand its technical meaning. Furthermore, they missed to put an apostrophe in genitive construction patients right; thus, it did not agree as a compound subject with the predicate require. Consequently, they did not identify the noun phrase as a subject and incorrectly made concord with the noun patients and not the noun bill. Therefore, they used the verb require in a plural and not a singular form.

However, the majority of students corrected the verbal construction took care used in the pattern in the past tense to take care in the first sentence and added the relative pronoun who, which made a logical connection between the first and the second subordinate clause. Also, the majority of students changed the infinitive construction have be treated that was incorrect to have been treated. They also realised the mistake made in the fourth sentence referred to the lack of agreement between the subject and the predicate (assault are > assault is). They noticed the spelling mistakes in the pattern (asault $>$ assault, verble $>$ verbal, negligense $>$ negligence). Furthermore, they recognised the subject of this sentence as a noun phrase, correctly treating discussing information about patients without their consentas a noun construction. Accordingly, they used an adverb to describe a situation instead of using an adjective, and they also harmonized a demonstrative pronoun with a plural noun (this areas $>$ these areas). All the clarifications above in the text indicate that students perceive mainly grammar and spelling mistakes and that functional and pragmatic views of their attention have not been yet developed.

In this view, the students were instructed to read the text once more trying to pay closer attention to the logical sections in the text, especially to the second sentence, where they had to find the subject. The majority of students identified the noun patient as the subject, not the entire phrase The Patients' Bill of Rights, probably because they do not know that subjects occur in a sentence both as simple or compound, i.e. that compound subjects may include phrases or syntagmas, but only the noun in nominative case is the logical subject that may interfere with other nouns or other types of words building a phrase. Furthermore, even if they perceive it as a phrase when talking about legislation, they mostly associate it with the noun law, not the noun bill, bearing in mind that they usually have in mind words literal meaning although the noun bill is used with a figurative meaning. Therefore, the students did not recognise it as a phrase and did not succeed to make a concord between the subject and the predicate (The Patients' Bill of Rights require $>$ The Patients' Bill of Rights requires). Also, they did not add the apostrophe to the plural noun in the construction patient bill $>$ patients 'bill in the first sentence, because they did not realise which of the words is the logical subject. Finally, referring to a group of people having some rights, we usually do not think about the importance of this matter in the singular. Thus, it would be better to use the noun in the plural as patients, not patient, bearing in mind that Bill of Rights is referred to all patients. Also, as we refer to the law, it will be written in English in capital letters.

Hereafter, we can see the students' mistakes with suggested corrections (Table 1). Consequently, we may conclude that the majority of mistakes that students made in writing are grammar mistakes $(8-1.04 \%)$, then spelling $(4-0.52 \%)$ and orthographic mistakes $(1-0.13 \%)$. 
Table 1 Students' mistakes in the first review with suggested corrections

\begin{tabular}{|l|c|}
\hline Orthographic mistakes with suggested corrections: & 1 \\
1. patients bill of rights / Patients bill of rights $>$ The Patients' Bill of Rights & $(0.13 \%)$ \\
\hline Spelling mistakes: & 4 \\
2. asault $>$ assault; verble> verbal; negligense > negligence; legaly > legally & $(0.52 \%)$ \\
\hline Grammar mistakes: & \\
1. took care > take care & \\
2. The Patients' Bill of Rights require > The Patients' Bill of Rights requires & \\
3. assault are> assault is verbal & 8 \\
4. patients right > patients' rights & $(1.04 \%)$ \\
5. have be treated > have to be treated & \\
6. discussing information about patients without their consent is unlawfully $>$ & \\
discussing information about patients without their consent is unlawful & \\
7. informations > information & \\
8. this areas >these areas & \\
\hline
\end{tabular}

Finalising the text, the students were asked to return to the specifics of the topic in order to improve text readability and meet the pragmatic points. They were also assisted with fundamental remarks of the lecturers that are discussed hereafter.

Bearing in mind that patients' rights are one of the main specifics of this topic, the students were advised to use more argumentative modal verb must instead of the modal verb have to in order to draw attention to adequate patient treatment. In addition, the noun respect was considered with students in the light of the comprehensive relationship between patients and health care practitioners and consequently, it was replaced with a noun dignity. In order to reconsider readability, the students were invited to notice that the last two examples in the fourth sentence were represented with the longer genitive form of analytic or Norman (French) genitive. To summarize the end of the sentence, they were suggested to change it with synthetic (Saxon) genitive in the last example (abuse of verbal communication > verbal communication abuse). In the fifth sentence, the students had to find the relative pronoun. They were suggested to avoid relative pronoun that and to use gerund form (Assault is a verbal or physical treat that cause injury or fear > Assault is a verbal or physical treat causing injury and fear). In the sixth sentence, the infinitive construction failure to obey these areas would be better to be replaced with gerund instead of infinitive construction (Failure to give proper care to > Failure of giving proper care.... is called negligence). In the last sentence, in order to generalise the conclusion leading to more formal tone, we should change the personal pronoun you with one/people (Failure to obey these areas makes you > Failure to obey these areas makes one / makes people non-liable or legally irresponsible).

In the second phase of finalising, as the students were invited to do it by themselves, their text reformulation met only the technical requirements of readability. The students' final version has only the body, but not the introductive part despite being advisable to introduce readers to general points. Given that an argumentative text focused on health care and patients' rights is relating to law implementation, we have to define the connection between health care and human rights and the role of legislation in managing health care requirements and health policy. It has to be explained in a simple but very sound way to point out the importance of liability of the health care system. This 
correlation was mentioned in the body of the text by using the phrase managing health care legislation instead of using the organisation of health care service, that sounds completely awkward and wrong both to professionals and people less introduced into the matter. Consequently, this change made in the last review will define clearly that as governments regulate or manage laws, health professionals will further manage health care and the attitude of every health care practitioner will be managed by implementing and respecting the rules that were established by governments.

There were also other changes introduced in the last review:

- The connection in the students' review made between the second and the third sentence with gerund construction was replaced with a preposition (having > with) in the last review. The preposition was suggested to highlight the meaning of the adverb clearly, referred to defining roles for all health team members, that is the key aspect for efficient health care.

- In order to draw attention to crucial laws regarding patients' rights and their health care, an apposition was added in the fourth sentence.

- As the fifth sentence is logically connected with the previous sentence, a connective phrase was used.

- The categories of violations were classified as criteria, not only as randomised types of breaches that indicated the determiner some.

- In order to make a substantial conclusion, we had to connect the body of the text with the last sentence using a more appropriate connective phrase that will announce to readers that significant arguments will follow. Therefore, consequently was used as one of the solutions.

- To attain more formal tone and to generalise the conclusion, instead of using the singular noun failer, we used the gerund construction failing.

- Also, the present tense construction was replaced with future tense construction in order to draw attention to the consequences of failing to obey these criteria. Also, the verb make was associated with the adverb certainly.

- Furthermore, as the conclusion may include the crucial aspects regarding the patients' rights, the last paragraph will be completed by using the subordinate preposition due to, instead of the less formal because of. This change will point out the importance of respecting the higher standards of human rights as well as of not breaking them and futuremore profound consequences due to their disobedience.

According to the students' reviews, we may conclude further that even the students made a few logical connections by using connectives, they did not realise the pragmatic aspects of the matters, their real significance and interactiveness in modern health care practice. Consequently, they made no review of the specifics by considering them in a more argumentative way, i.e. they inserted no argumentative text or supportive linkers in order to re-evaluate the facts (e.g. we do not see the connection between the government's role and health care practitioners in practice, and while reading, it seems that all facts and definitions were given at random). Eventually, their review has no argumentative conclusion that will help the readers in understanding it more pragmatically. Undoubtedly that even the students were on the third and fourth year studyingthe matters of health care management, they did not evaluateessential target points that must be underlined as very important in managing health care. 


\section{CONCLUSION}

As this paper evaluated the level of proficiency in academic writing of the third and the fourth year students of medical sciences, with a special attention on their capacity to pragmatically review their written communication, we may conclude that for improving their pragmatic approach in any content, especially in medical aspects, health care practitioners have to be directed to several points: 1 . an evaluation of the importance of moral and ethical values and their complexity in providing health care, as they lead to the real outcomes of health care; 2. teaching students how to highlight them in academic communication, especially in written communication.

Pointing out the importance of moral and ethical values in medical sciences is extremely important due to a lot of unethical interests that nowadays often prevail in medical care. Therefore, the specific approaches of modern health care in the light of its comprehensiveness have to be explained to be applied in academic and professional communication in health care. Communication as an instrument in the treatment of the patient is an indispensible key segment in this holistic, comprehensive approach. Consequently, this significant foundation will undoubtedly help the health care practitioner to communicate verbally or in writing in an adequate manner.Exactly as stated in Naughton C. A. when refers to pharmacists $(2019: 4,6)$ : "Some patient-centred improvements have been made in health care services, but optimal health has not been fully realized. Only when pharmacists have a holistic understanding of an individual patient, including their experience of illness and medication, can they effectively assess appropriateness, safety, efficacy, and adherence to medications and develop realistic treatment plans. (...) In other words, "the pharmacists must maintain a high level of humility about their scientific knowledge so that the knowledge of the patient can be recognized."

\section{REFERENCES}

Faber P. San Martín A. Specialized Language Pragmatics, Research Gate >file:///C:/Users/ leontina/Downloads/spepragmaticssani.pdf > (26 June 2019)

Käalvemark S. Kaae S.S. Communication in Pharmacy Practice (Basel: Editorial Office MDPI), 2019, 4-6

Leki I. Academic Writing, Exploring Processes and Strategies. Cambridge: Cambridge University Press, $2^{\text {nd }}$ edition, 1998, 216-232

Morón R. et al. Pragmatics Applied to Language Teaching and Learning, Cambridge Scholars Publishing, 12 Back Chapman Street, Newcastle upon Tyne, NE6 2XX, UK, 2009 <https://www.cambridgescholars.com/download/sample/60065>(17 September 2019)

Ursache I. Get Ready for Academic Writing, Bucharest: Polirom, $1^{\text {st }}$ edition, 2007, 113-163 